\title{
A teoria da dependência nas perspectivas de Celso Furtado, Fernando Henrique Cardoso e Ruy Mauro Marini
}

\author{
Silvio A. F. Cario * \\ Márcio G. Gomes ** \\ Eduardo S. Sigaúque ***
}

\begin{abstract}
Resumo
O objetivo desse artigo é discutir a teoria da dependência sob as abordagens dos autores brasileiro Celso Furtado, Fernando Henrique Cardoso e Ruy Mauro Marini. Esta concepção teórica insere-se na discussão do subdesenvolvimento que marca as economias periféricas em geral, e a brasileira em particular. Em termos metodológicos, recorreu-se a abordagem analítica a partir das obras desses autores. Enfatizou-se a dependência cultural em Furtado, em face do desenvolvimento ocorrer atrelado aos valores e ideologias do centro capitalista desenvolvido. $\mathrm{Na}$ concepção de Cardoso, a dependência assume natureza política, expressa pelos vínculos políticos que amarram interesses econômicos nacionais aos estrangeiros. Enquanto, para Marini, a dependência é econômica enquanto instrumento de dominação e exploração dos países capitalistas imperialistas sobre as economias periféricas.
\end{abstract}

Palavras-chave: Subdesenvolvimento; Dependência; Celso Furtado; Fernando Henrique Cardoso; Ruy Mauro Marini

\begin{abstract}
The aim of this article is to discuss the theory of dependency under the approaches of the Brazilian authors Celso Furtado, Fernando Henrique Cardoso and Ruy Mauro Marini. This theoritical conception is part $\mathrm{f}$ the discussion of underdevelopment thar marks peripheral economies in general, and Brazilian economies in particular. In methodological terms, na analytical approach was used based on the works of these authors. Cultural dependence in Furtado was emphasized, in view the development occurring linked to the values and ideologies of the developed capitalista center. Cardoso's conceptions, dependency takes on a political nature, expressed by political ties that tie national economic interests to foreigners. Whereas, for Marini, dependency is economic as an instrument of domination and exploitation of imperalist capitalist countries over peripheral economies.
\end{abstract}

Key-words: Underdevelopment; Dependency; Celso Furtado; Fernando Henrique Cardoso; Ruy Mauro Marini

Classificação JEL: O1; O10

\footnotetext{
* Professor Titular vinculado aos Programas de Pós-Graduação de Economia e de Administração da Universidade Federal de Santa Catarina (UFSC). E-mail: fecario@yahoo.com.br

** Mestrando do Programa de Pós-Graduação de Economia da Universidade Federal de Santa Catarina (UFSC) E-mail: economiamarcio@gmail.com

*** Doutorando do Centro de Desenvolvimento e Planejamento Regional (CEDEPLAR) da Universidade Federal de Minas Gerais (UFMG). E-mail: eduardo.sigauque @ cedeplar.ufmg.br
} 


\section{Introdução}

A teoria da dependência emerge como uma formulação teórica desenvolvida na América Latina, no decorrer da década de 1960, com o intuito de compreender as características estruturais dos países inseridos, tardiamente, no sistema capitalista de produção. Na medida em que não se confirmaram as expectativas atribuídas aos supostos efeitos irradiantes da industrialização, via substituição de importações, colocou-se em cheque a teoria que até então serviu de inspiração para o estilo de desenvolvimento nacional e autônomo, implementado nos anos precedentes, sob a égide da Comissão Econômica para o Desenvolvimento da América Latina e Caribe (CEPAL). Tal conjuntura culminou no surgimento de um movimento de críticas, reparos e autocríticas às premissas do industrial-desenvolvimentismo, prescrito por aquela instituição.

Não obstante, o debate sobre dependência e desenvolvimento já vinha ocorrendo em discussões acerca do desenvolvimento e subdesenvolvimento, no imediato pós II Grande Guerra, com destaque para as décadas de 50 e 60 (PRADO, 2015). No curso desse debate, segundo Fiori (1999), não surgiu uma, mas várias teorias da dependência, e cada uma apontando para projetos políticos e estratégias econômicas diferentes. Nesse contexto, ganhava espaço na cena teórico-analítica, como crítica, a visão estruturalista, inicialmente, apresentada por Celso Furtado, que após passagem pela CEPAL, aprofundaria sua análise explicativa; e por Fernando Henrique Cardoso, em coautoria com Faletto e outros, com passagem pelo Instituto Latino Americano de Planejamento Econômico e Social, organismo interno da CEPAL. Nesse contexto, destacava-se, também, o tratamento fundado em um projeto de desenvolvimento nacional autônomo, de autoria de Ruy Mauro Marini, do Centro de Estudos Socioeconômicos (CESO) da Universidade do Chile.

Muito tempo se passou desde as primeiras formulações teóricas da dependência até os dias atuais, e as economias latino-americanas continuam amarradas ao atraso e com o desenvolvimento sendo marcado por deformação estrutural, simbolizada em significativa heterogeneidade socioeconômica. Discutir, novamente, as matrizes das interpretações de Furtado, Cardoso e Marini constitui o objetivo desse artigo. Busca-se, assim, demonstrar, em cada autor, as categorias analíticas centrais, que sustentam o argumento principal, assim como, conforme cada autor propõe forma distinta, superar e ou desenvolver a economia sob esse signo.

Para tanto, o artigo encontra-se dividido em cinco seções, sendo que, nessa primeira, aponta-se o seu propósito; na seção dois, discute-se a dependência cultural segundo Furtado; na 
seção três, apresenta-se a visão de dependência política na visão de Cardoso; na seção quatro, analisa-se o tratamento marxista da dependência, de acordo com Marini; e, por fim, na seção cinco, apresentam-se as considerações finais.

\section{Dependência cultural segundo Furtado}

Em sua vasta obra, Furtado teve como uma das preocupações acadêmicas centrais compreender os motivos que impedem a superação do subdesenvolvimento brasileiro. No curso de sua vida, inquietava-o a presença de características que marcam o subdesenvolvimento, como: a desigualdade social, a heterogeneidade econômica estrutural, e a submissão à ordem capitalista mundial. Para tanto, busca compreender o processo de conformação estrutural e as decisões tomadas, historicamente, pelas economias. Não sem razão, afirma que "[...] para compreender o processo de desenvolvimento é indispensável identificar os agentes responsáveis pelas decisões estratégicas e reconhecer os fatores estruturais que condicionam a propagação dos efeitos de tais decisões" (FURTADO, 1983, p.81) no contexto da economia mundial.

Nessa leitura, para Furtado, o desenvolvimento deve ser interpretado a partir da análise da estrutura econômica e dos sujeitos que tomam decisões em contexto histórico, implicando a construção de trajetória autônoma do país. Assim, explicita-se o sistema de dominação reinante, seu relacionamento com os níveis da estrutura social, bem como os meios de sua reprodução (FURTADO, 1980). Nesse curso, o desenvolvimento gera seu contrário, isto é o subdesenvolvimento, sendo considerado não como uma fase ou etapa, mas decorrente do próprio processo de transformação, que ocorre na economia mundial capitalista. Em continuidade observa que o subdesenvolvimento expressa uma deformação estrutural, na medida em que se produz um sistema de dominação de determinado segmento social sobre outro, num contexto de exclusão econômica e social de parte significativa da sociedade, distanciada dos frutos do desenvolvimento.

No propósito de compreender o processo de desenvolvimento capitalista e a forma como adentra a área periférica, Furtado recorre à história para explicar a expansão do capitalismo industrial, a partir dos anos 1700 na Europa, estendida à América do Norte e, depois, para outras áreas territoriais. Nesse contexto, aponta direções do desenvolvimento, identificando que, na primeira expansão capitalista, houve uma desorganização na economia artesanal, liberando mão de obra e promovendo absorção desta para novas atividades, concomitante ao desenvolvimento 
de tecnologia compatível com esse fator produtivo. A segunda expansão ocorre para alémfronteira europeia, mas com características produtivas semelhantes; enquanto, a terceira fase, é marcada pela difusão desse modelo industrial europeu para economias de natureza précapitalista em outras áreas. No início, através de interesse comercial, obtendo matéria-prima e gerando impactos locais no volume de absorção de mão de obra; e, posteriormente, via indústria, promovendo maiores alterações na estrutura econômica (FURTADO, 2000; LINS, 2013).

Dessa compreensão, aponta que o desenvolvimento capitalista, no Brasil, constituía um caso híbrido, diferente de outras estruturas pré-capitalistas. Aqui, no início, os salários ligados ao comércio internacional dinamizaram o mercado interno, com hábitos de consumo ligados na aquisição de bens importados, criando condições de expansão comercial doméstica. Em paralelo, seguiram-se os lucros da atividade cafeeira, investidos nessa atividade, cuja expansão possibilitou a promoção da econômica de subsistência e a demanda por manufaturas advindas de produção interna, criando, base para expansão industrial. Assim, ao longo do tempo, foi se formando base produtiva via substituição de importações, fundada em indústria de bens de salários (MELLO, 1983; SUZINGAN, 1986).

O desenvolvimento, nesse caso, vinha de fora para dentro e impunha dinâmica dentro da economia doméstica; e, com o tempo, a dinâmica interna passou a se autorreproduzir. Contudo, como afirma Lins (2013), essa autorreprodução aconteceu sem que tivesse uma etapa superior de desenvolvimento industrial, advinda da produção de equipamentos necessários para expansão da capacidade produtiva, em linha com o atendimento das necessidades da população em geral, o qual ocorria via importação dos bens de produção. A dependência do padrão produtivo e tecnológico dos países detentores de bens de capital, combinada com a falta de estratégia de desenvolvimento autônomo interno, marcou, desde o início, o desenvolvimento industrial brasileiro dependente.

Nessa perspectiva, o processo de industrialização adotado no país inclina-se em repetir o padrão tecnológico dos países centrais, onde a indústria se encontrava desenvolvida. Adotase, no Brasil técnicas intensivas e capital semelhante ao investido nas economias centrais, cuja produção destinava-se a certa parcela da população (ALMEIDA, 2009). A partir desse contexto, como observa Furtado (1992), declarava-se o impedimento de organizar a produção em outra direção, sob outro propósito desenvolvimentista. Cria-se, internamente, um sistema cuja reprodução modernizava a base produtiva, porém, destinada para determinado segmento social, causando, por consequência, forte heterogeneidade social, decorrente da exclusão de acesso, de 
grande parte da população, aos bens e serviços gerados. Sob esse sistema, não se constata a homogeneidade social desejada, visto a grande maioria das pessoas não ter acesso, de forma correta, ao atendimento das necessidades alimentares, de vestuário, de moradia, de acesso à educação, ao lazer e a atividades culturais.

Tal quadro demonstra que a economia desenvolvida sob condições de subdesenvolvimento reproduz, sistematicamente, cópia de vida de outras sociedades, com benefícios para determinado estrato social, que tem ganhos decorrentes da produtividade obtida com tecnologias forâneas, alheias à realidade econômica e social periférica. Ao se reproduzir esse sistema no interior das economias subdesenvolvidas, a modernização decorrente não é abrangente, mas, seletiva, segregando parte da sociedade. Nesse sentido, Furtado (1974) afirma que "[...] a teoria do subdesenvolvimento cuida do caso especial de processos sociais e que aumentos de produtividade e assimilação de novas técnicas, não conduzem a elevação do nível de vida médio da população". Assim, a produtividade, embora seja importante para o processo de desenvolvimento, não se confunde com o desenvolvimento, pois não se traduz em benefício geral à sociedade (LINS, 2013).

Para Furtado (1972, p. 27), “[...] nas economias subdesenvolvidas, não houve uma correlação entre os aumentos da produtividade, engendrados pela elevação da relação capitaltrabalho e pela adoção de novas técnicas de produção, e o crescimento da massa salarial, fatores esses que estão na base das economias industriais modernas". Nessas economias, o padrão produtivo adotado constituia-se apropriado para uma pequena parcela da população, que se beneficiava com a diversificação dos produtos gerados, em linha com a alta renda correspondente. Situação distinta observada nos países capitalistas centrais, cujo padrão de produção, impulsionado pela inovação tecnológica, promovia elevação da produtividade, que se estendia em melhoria de vida para a população em geral, seja via aumento da taxa de salário em linha com a produtividade, seja através da diminuição dos preços relativos dos bens de consumo (ALMEIDA, 2009).

A constituição deformada das economias subdesenvolvidas levou a dominação dependência, por impor um padrão ditado por progresso técnico forâneo. Sampaio Jr, (1999) na leitura das obras de Furtado, em comparação com outros pensadores nacionais - Caio Prado Junior e Florestan Fernandes -, aponta o caráter submisso da dependência a que estavam submetidas as economias subdesenvolvidas, como reflexo do progresso tecnológico advindo dos polos dinâmicos da economia mundial. Nesse sentido, tal dinâmica impôs um padrão de consumo submisso, exclusivo e provocador de heterogeneidade social, condicionando, assim, 
o desenvolvimento. A esse respeito, Furtado (1971, p. 342-343, apud Almeida 2009, p. 114) afirma que "el control del progresso tecnológico y possibilidad de imponer patrones de consumo, de parte de uno o de algunos subsistemas, viene a condicionar la estructuración del aparato productivo de los demás subsistemas, los cuales se vulven dependientes".

O padrão de produção adotado exigiu, por seu turno, um perfil de demanda restringida, a qual, para atender o mercado de consumo de alta renda, requereu a promoção de concentração de renda em favor de classe mais rica, que garantisse poder de compra a esse grupo seletivo. Conforme Furtado (1974, p.78, apud Almeida, 2009, p. 116-117): “A combinação de tecnologia poupadora de trabalho com elasticidade da mão de obra permitiu que os aumentos de produtividade, engendrados pela difusão do progresso técnico e pelas economias de escala, impulsionassem a concentração de renda em favor das classes mais ricas”. Nesses termos, Furtado entendia o desenvolvimento econômico como "simplesmente inalcançável [...] a ideia do desenvolvimento econômico é simplesmente mito [...] a transição do subdesenvolvimento para o desenvolvimento é dificilmente concebível no quadro da dependência” (p. 87).

Na concepção de Furtado, os países geradores de inovação tecnológica influenciam os valores culturais e os padrões de consumo das sociedades periféricas, na medida em que, ao ingressar nessas economias periféricas, criam um sistema dualista estrutural - cultural. Nesse curso, criam-se um setor moderno avançado, que imita padrões culturais impostos pelos países desenvolvidos; e um setor marginalizado, atrasado em relação aos padrões modernos de desenvolvimento. A penetração das técnicas modernas de produção dá origem a um setor possuidor de produtividade elevada e altos salários; e outro rudimentar, com baixos níveis de produtividade e salários de subsistência (IPIRANGA; AREND, 2020). Em linha com o pensamento furtadiano, Albuquerque (2009) expõe que a adoção de tecnologias produzidas no centro das economias periféricas gera polarização modernização-marginalização. De um lado, tem-se estrutura que produz bens de luxo, possibilita acesso a artigos importados e garantia de bem-estar; e, de outro, estrutura que produz bens de salário, desemprego estrutural e heterogeneidade social.

Sob o contexto desse dualismo, a minoria social dominante periférica, que se identifica com valores culturais e ideológicos do centro, mais do que os próprios valores nacionais, estende sua ação reprodutora na sociedade. Diante do controle do poder que exerce e da posse de capital que tem, essa minoria subjuga os demais estratos sociais, em nome da manutenção de valores distantes da realidade nacional (CAETANO; MISSIO, 2017). Além disso, desenvolve, internamente, regramentos econômico e social - incentivo, apoio, favorecimento - 
que reproduzem o status quo dominante. Produz valores que levam as pessoas a terem o sentimento de que se esforços forem realizados, poderão se igualar e até superar outros. Mecanismos propagadores não faltam. Dentre os instrumentos utilizados, encontra-se o sistema de propaganda e comunicação, tanto como estimulador do consumo da indústria cultural dominante, como via sistema de acesso aos produtos fabricados pelo setor moderno no mercado, via sistema financeiro facilitador.

Eis que se incorpora, na economia periférica, um processo de emulação, cujo efeito demonstração difunde e legitima padrões de produção e consumo, de estratificação superior da estrutura social. Como observam Vilaça e Conceição (2018), a elite periférica tem consumo conspícuo, cuja difusão é vista como um padrão superior de vida, almejado pelos estratos inferiores. O padrão de vida de uma minoria é sonhado e desejado pela maioria na sociedade. Tal emulação se propaga como convenção social na economia periférica, e, como efeito dominó entre os vários estratos sociais, consolida-se como padrão, mascarando a diferenciação social entre os indivíduos. Logo, "a dependência não se manifesta somente no âmbito econômico, mas também, como um aspecto da evolução social e cultural da sociedade periférica" (VILAÇA; CONCEIÇÃO, 2016, p. 12). Na análise de Caetano e Missio (2017), diante da produção e reprodução de ações reprodutora do status quo, dificulta-se a consolidação de uma identidade nacional e o estabelecimento de interesse comum na sociedade.

Nesse processo, as decisões de investimento e de adoção do progresso técnico são guiadas e ditadas pelo padrão externo, numa forma e ritmo que não permitem a promoção de mudança estrutural, que conduza a superação do subdesenvolvimento. Destarte, o sistema econômico, "que seria lavado a cabo pela criatividade por inovações tecnológicas promovidas pelos empresários nacionais" (Arend et al., 2019), é comandado pela demanda do setor moderno da economia, guiado pelo estilo de vida estrangeiro e não pela oferta. A dinâmica da acumulação ocorre pelo mimetismo cultural do centro, que gera determinada histerese interna, posta pela forma com o sistema econômico é dotado de capacidade de preservar uma deformação estrutural, efetuada por determinado estímulo externo. Com isso, dificulta o desenvolvimento de condições voltadas a superar as situações que geram o subdesenvolvimento, ampliando, por consequência, o abismo social criado por essa deformação estrutural do desenvolvimento.

Nesse contexto, reproduz-se a dependência via constante modernização do padrão de consumo, em linha ditada pelo padrão estrangeiro dominante. Novos produtos e novos processos são introduzidos como característica do processo produtivo de concorrência, mas sob 
a mesma lógica dependencista. Tal permanência renovada é uma forma de manter o aprisionamento instrumental cognitivo, que constrange o desenvolvimento da criatividade na sociedade. Por conseguinte, a dinâmica inovativa periférica resume-se em desenvolver ações imitativas, de fácil caminho, ancorada em estrutura de incentivo, a ter que desenvolver processos rotineiros de busca por inovações, que rompam o status quo. Como observam Ipiranga e Arend (2020, p. 02): "Hábitos emuladores dos agentes locais, enraizado secularmente nos processos cognitivos da sociedade levam as empresas a desenvolverem 'genes pouco criativos', limitando em termos microdinâmicos, a liderarem revolução tecnológica schumpeteriana".

Nesse curso, o desenvolvimento de uma nação somente tem sentido, quando superada a dependência cultural, que a leva ao subdesenvolvimento. Desse modo, “[...] a dependência trava o processo de homogeneidade social e, por conseguinte, o acesso aos direitos fundamentais da vida, a utilização deformada de recursos produtivos domésticos e, em última instância, a uma posição marginal e subordinada na economia mundial, dificultando a constituição de uma Nação (BRANDÃO, 2012, p. 8). Assim, levanta-se a questão: Como superar a dependência que trava o processo de homogeneidade social? Furtado aponta que requer, antes, saber se desejamos continuar sob essa posição de dependência ou se há disposição em superá-la. Nessa linha, observa: “[...] continuaremos a contribuir para o enriquecimento do patrimônio comum da humanidade ou seremos relegados ao papel passivo de simples consumidor de bens culturais adquiridos no mercado. Ter ou não acesso à criatividade, eis a questão" (FURTADO, 1999, p. $53)$.

Para Furtado (1984, p. 28), o caminho de superação do quadro atual passa pela dimensão política, ressaltando que "somente a vontade política será capaz de canalizar as forças criativas para a reconstrução de estruturas sociais avariadas e a conquista de novos avanços na direção de forma superior de vida". Com isso, o papel requalificado do Estado ganha relevância, por ser capaz de direcionar um aparato criativo que permita encontrar caminhos que levem a formas de ação em busca da homogeneidade social (PACHECO; BENINI, 2018). Criar condições de estabelecer estruturas sociais que abram espaço à criatividade, em amplo espaço cultural e que "libere a criatividade; [...] a fim de que ela possa servir ao pleno desenvolvimento de seres humanos, concebidos como fim, portadores de valores inabaláveis" (FURTADO, 1998, p. 66, apud PACHECO; BENINI, 2018, p. 329). Para tanto, o Estado precisa ser requalificado. Essa instituição deve ser capaz de criar espaço que permita aflorar a criatividade na sociedade, e, com isso, encontrar caminhos que promovam a homogeneidade social. 
Contudo, Furtado aponta a necessidade de construir uma política de desenvolvimento, assim expressa: "A superação do impasse com que nos defrontamos requer que a política de desenvolvimento conduza a uma crescente homogeneização de nossa sociedade, e abra espaço para a realização das potencialidades de nossa cultura" (FURTADO, 2000, p. 36). Requer, portanto, deparar com grande desafio, dado que existe um sistema de poder e de domínio do capital que reproduz as condições do subdesenvolvimento. Essa, com certeza não é tarefa fácil. Exige-se uma nova forma de exercício de poder e requer organização, coordenação e controle pelos centros de decisão, que permita aflorar a criatividade da sociedade. Novamente, a presença do Estado é fundamental, alargando o horizonte de possibilidades de mudanças, criando condições desenvolvimentistas em linha com as aspirações nacionais. Nessa perspectiva, Brandão (2012) aponta que o Estado deve estabelecer estímulos à promoção da identidade, diversidade, diferenciação e variedade, advindos de participação cidadã em arenas de interesses voltadas a discutir caminhos de uma sociedade mais justa, igualitária e fraterna.

\section{A dependência política na visão de Cardoso}

Adentrar a teoria da dependência sob a ótica de Cardoso requer, primeiro, repensar a concepção de desenvolvimento que permeia as elaborações teóricas do autor. Segundo Cardoso e Faletto (1975, p. 16), “o desenvolvimento é em si mesmo um processo social; mesmo seus aspectos puramente econômicos deixam transparecer a trama de relações sociais subjacentes". Assim, é insuficiente limitar-se às análises baseadas nos esquemas econômicos do desenvolvimento, dada a dimensão social inerente. Mais do que isso, a análise do desenvolvimento requer um duplo esforço: por um lado, considerar, em sua totalidade as condições históricas (econômicas e sociais) particulares de cada economia; e, por outro, compreender, dadas as situações estruturais específicas, "os objetivos e interesses que orientam ou animam o conflito entre os grupos e classes e os movimentos sociais que 'põem em marcha' as sociedades em desenvolvimento" (p. 21).

A partir de uma formulação que transcende o estritamente econômico, Cardoso (1964) destaca que o capitalismo monopolista, dominado pelas grandes corporações, implica economias, cuja feição é cada vez mais política, de modo que o controle da propriedade está intrinsecamente associado à formação de grupos de pressão, que atuam no interior das empresas, e ao poder de decisão, que resulta das alianças entre os grupos econômicos. Desse modo, a compreensão da mudança na estrutura das economias periféricas da América Latina 
suplica o entendimento do processo histórico, o que não significa a interpretação ingênua ressaltam Cardoso e Faletto (1975) - da importância da sequência temporal para a explicação científica, "mas que o devir histórico só se explica por categorias que atribuam significado aos fatos e que, em consequência, sejam historicamente referidas" (p. 22).

Nesse contexto, a análise do desenvolvimento deve ser alcançada a partir de perspectiva que a vincule, concretamente, à análise das relações entre os grupos sociais, os componentes econômicos e os sociais. Assim, ao estudar as estruturas de dominação e as formas de estratificação social, que condicionam os mecanismos e os tipos de controle e decisão do sistema econômico, a análise do desenvolvimento, a partir da perspectiva sociológica, apoiase, fundamentalmente, na compreensão dos movimentos e das forças que constituem cada situação particular. Esses movimentos de luta política e econômica, que se desdobram na esteira do processo histórico, constituem a matéria prima da qual partem as análises da dependência.

O conceito de dependência, nesse sentido, objetiva conferir significado a um conjunto de fatos e situações que se manifestam, de forma conjunta, em dado momento do processo histórico e, a partir deles, buscar se entender como se dão as relações que tornam inteligíveis as observações acerca da realidade econômica e social. Compreender tais vínculos, que se dão a partir da conexão entre componentes estruturais internos e externos, pressupõe centrar a análise da dependência na manifestação interna resultante Desse modo, o desenvolvimento deve ser entendido como resultado de interações de grupos e classes sociais que demonstram seus interesses materiais e valores distintos, em movimentos de conciliação ou superação que ocorrem no sistema econômico (CARDOSO; FALLETO, 1975).

Por essa lógica, as mudanças nas estruturas sociais e políticas, que permeiam a estrada do desenvolvimento, sucedem da luta entre os atores sociais, na medida em que estes conseguem impor seus interesses sobre o conjunto da sociedade. Considerando tal compreensão, Cardoso (1959) avalia o movimento político e econômico do processo de industrialização no Brasil do pós-guerra. O acelerado processo de industrialização em curso permitia a incorporação maciça de trabalhadores nas atividades urbano-industriais, a expansão de serviços e das atividades terciarias nas cidades, e o fortalecimento do mercado interno. Nessa perspectiva, formavam-se, em solo brasileiro, as condições que permitiriam o crescimento relativamente autônomo do setor industrial, a remoção das estruturas atrasadas e a afirmação do modelo de desenvolvimento nacional e autônomo, capaz de promover a superação do subdesenvolvimento. Essa transformação, impulsionada pela industrialização, é assim descrita: “o processo de crescimento industrial significará [...] a transformação de uma economia de base 
agrária [...] numa economia nacional de base capitalista que se desenvolve numa sociedade de classes, onde a indústria torna-se, ao lado da agricultura, um componente essencial do mecanismo econômico" (CARDOSO; IANNI, 1959, p. 144, 1959).

A coincidência dos interesses políticos e econômicos das massas, do capital externo e da política protecionista de Juscelino Kubitschek, e a expectativa de que a industrialização autônoma seria a tábua de salvação para o desenvolvimento nacional, porém, caem por terra a partir do início dos anos 1960, quando a economia brasileira entrava em forte desaceleração, sobretudo no setor industrial, cuja taxa média de crescimento declinou da ordem de $11 \%$ ao ano, entre 1955-61, para 1,8\% ao ano entre 1962-66. A esse ambiente econômico somou-se a crise política com a perda de apoio do executivo junto a outras esferas, dentre as quais no poder legislativo e junto as organizações representativas na sociedade (CARDOSO; FALETTO, 1975).

Assim, o enfrentamento à crise poderia se dar a partir da ocorrência de uma das três situações: i) o setor industrial impor sua hegemonia, exercendo controle sobre o Estado no sentido de atender as demandas deste setor; ii) o Estado populista assumir o enfrentamento da crise, visando conciliar os interesses da burguesia urbano-industrial e das massas, o que, deveras, não seria tarefa fácil dado o acirramento da luta de classes; ou iii) caso se consolidasse uma aliança entre a burguesia industrial e a burguesia agroexportadora. Algumas dessas possibilidades foram, de fato, tentadas (ainda que parcialmente), todavia não cabe aqui avançar sobre as especificidades de cada uma. $\mathrm{O}$ aspecto fundamental a ser destacado é: fosse qual fosse o cenário, a associação com o capital estrangeiro seria inevitável (CARDOSO; FALETTO, 1975)

Segundo Cardoso (1964, 1975), faltava ao Brasil uma classe hegemônica com mentalidade moderna, capaz de assumir a liderança do processo de desenvolvimento. Entre os principais obstáculos, o autor destaca: a fraca visão empresarial dos grupos industriais; o pouco conhecimento da realidade política do país; a pouca participação no sistema do poder; o pouco conhecimento técnico; a obsessão pelo lucro imediato; a falta de perspectiva inovadora; entre outros (ALMEIDA, 2009). Cardoso (1964, p. 41) manifesta a inviabilidade do desenvolvimento sob a condução da burguesia nacional em termos pragmáticos: "Não se pode esperar, por outro lado, que nestas últimas áreas, o empreendedor repita, simplesmente, a história dos homens que fizeram o desenvolvimento do capitalismo no período clássico".

$\mathrm{Na}$ medida em que se verifica, em alguns ramos da atividade industrial, a mentalidade tacanha da burguesia nacional, constitui-se como barreira às possibilidades de desenvolvimento 
do modo capitalista de produção. Dessa forma, a ausência de condições político-sociais para a imposição de uma ideologia industrializante, por parte do empresariado nacional, reforça a necessidade de associação ao capital estrangeiro. Nas palavras de Cardoso (1964, p. 177): "para desenvolver de fato a economia nacional, ela precisa apelar para a interferência de grupos que lhe são estranhos, que nem sempre têm interesse em desenvolver a economia do país em termos que permita sua hegemonia".

Enquanto no período precedente, do nacional-populismo, o desenvolvimento industrial orientou-se a partir da consolidação do Estado como instrumento de regulação e formação de setores produtivos. O ambiente pós anos 1960 e, sobretudo na sequência do golpe militar, suscita a reorientação do desenvolvimento na direção de uma acomodação subalterna ao sistema internacional, sob a liderança de grandes corporações estadunidenses. Para Martins (1968), “os setores industrializantes [...] acomodaram-se com relativa docilidade a essa reorientação ou com ela se solidarizaram expressamente" (p. 26, apud ALMEIDA, 2009, p. 56). Cardoso (1993, p. 87) enfatiza que fração "ponderável do empresariado nacional conspirava claramente com grupos estrangeiros, organizava-se politicamente e enfrentava ao mesmo tempo o sindicalismo nacional-populista e o governo que a esquerda acreditava ser da burguesia nacional”.

Assim, as articulações dos grupos econômicos e das forças sociais se traduzem num movimento de internacionalização do mercado que, por sua vez, reflete uma nova "situação de desenvolvimento" nas economias industriais-periféricas. Sob esse novo modelo, os laços entre centro e periferia não se restringem ao sistema de importações e exportações, mas se dão através de investimentos estrangeiros industriais diretos, nos novos mercados das economias periféricas. Segundo Cardoso (1964), embora sufocasse a atuação do empresariado local, a internacionalização representaria a possibilidade de impulsionar o desenvolvimento capitalista para a periferia, na medida em que provocaria uma redefinição no comportamento rudimentar e tradicional dos empresários brasileiros. Fica evidente, dessa maneira, a importância que Cardoso confere ao papel comportamental do empresariado nacional no processo de desenvolvimento.

A elevação no grau de diferenciação produtiva, que se supõe a partir desta nova situação, é capaz de promover desenvolvimento em termos de acumulação e transformação da estrutura produtiva. Vale ressaltar, esse contexto não prevê incremento da autonomia nacional sobre o processo de desenvolvimento, pelo contrário, aprofunda o caráter periférico e dependente, já que: [...] tanto o fluxo de capitais quanto o controle das decisões econômicas 'passam' pelo exterior; os lucros, mesmo quando a produção e a comercialização dos produtos realizam-se no 
âmbito da economia dependente, aumentam virtualmente a massa de capital disponível por parte das economias centrais; e as decisões de investimento também (CARDOSO; FALETTO, 1975, p. 126).

Do mesmo modo, o tipo de desenvolvimento associado ao capital financeiro internacional intensifica o "sistema social excludente que caracteriza o capitalismo nas economias periféricas" (CARDOSO; FALETTO, 1975, p. 124). Sobre esse aspecto, entretanto, Cardoso e Faletto ressaltam não haver contradição alguma ao se vislumbrar a ocorrência de desenvolvimento, posto que o entendimento marxista sobre o desenvolvimento (ou acumulação) capitalista pressupõe exploração, concentração de renda, espoliação e exclusão. Nesses termos, o desenvolvimento da economia dependente realiza-se, simultaneamente, ao aprofundamento das desigualdades sociais e regionais, o que retrata, simplesmente, a forma que o capitalismo industrial assume no contexto de uma situação de dependência (CARDOSO, 1993).

Em outras palavras, "a dependência constitui o modus operandi do capitalismo na periferia; trata-se de [...] uma constatação e não uma característica disfuncional que possa ser contraproducente à materialização do desenvolvimento ou mesmo torná-lo inviável" (ALMEIDA, 2009, p. 102). Os beneficiários desse tipo de desenvolvimento, aponta Cardoso (1993), formam o denominado tripé do desenvolvimento dependente-associado: as empresas estatais, as grandes corporações multinacionais e as empresas locais associadas a ambos.

A nova conjuntura de desenvolvimento dependente-associado redefine, também, as prioridades do Estado, que deixa de ser um Estado-populista para transformar-se em um Estadoempresarial: atuando, majoritariamente, como comprador e produtor, por meio das empresas públicas, e, de forma tímida, no fomento às políticas do tipo populista, que estimulam a redistribuição de renda e os aumentos salariais. Nessa linha, Cardoso (1964) argumenta que o “Estado se torna então tanto um instrumento que 'regula' a divisão do mercado entre empresas gigantes [...] quanto um meio de absorção dos excedentes econômicos: obras públicas, despesas militares, projetos tecnológicos de grande vulto etc" (p. 37). Mais a frente, todavia, sublinha: “é preciso que a Nação se veja representada no Estado e sinta as decisões deste como expressão de vontade coletiva, embora, de fato, o Estado continue a ser, nas resoluções fundamentais, instrumento da prosperidade dos capitalistas" (CARDOSO, 1964, p. 38). A atuação combinada do Estado junto do capital internacional, assim, opera no sentido de reforçar a tendência de desenvolvimento dependente. 
Dessa maneira, ao conjunto de fatores econômicos e políticos - expressos nas condições estruturais e na imposição de uma agenda industrializante em favor das elites nacionais e do capital internacional - soma-se à debilidade da capacidade de integração das massas operárias, cujas aspirações encontravam pouca unidade. Essa característica, para Cardoso (1964) não traz como novidade a existência da dominação externa, mas a caracterização da forma que ela assume, com parte do processo de subordinação das condições internas às externas. A teoria da dependência apresenta-se como "instrumento teórico para acentuar tanto o os aspectos econômicos do subdesenvolvimento quanto os processos políticos de dominação de uns países por outros, de umas classes sobre as outras, num contexto de dependência nacional" (CARDOSO; FALETTO, 1975, p. 139).

O que há de novo, portanto, é a consideração dos interesses de poder, das alianças para garantir hegemonia de grupos e facções de classe, internos e externos, no sentido de explicar as situações de dominação que, por certo, não se restringem ao grau de diferenciação logrado pelo sistema econômico periférico. Assim, levando-se em conta as condições dadas pelo processo histórico, a elaboração teórico-analítica de Cardoso vislumbra pouca concretude nas possibilidades de superação do modelo de desenvolvimento dependente-associado. Mais do que isso, conclui que a materialização do desenvolvimento das nações subdesenvolvidas só teria sentido com a colaboração das economias avançadas e com a conveniência dos capitais financeiros internacionais, o que, como já dito, não pressupõe melhoria das condições de vida para o conjunto da população.

\section{Tratamento marxista da dependência: uma leitura contemporânea de Ruy Mauro Marini}

No que se refere à teoria marxista da dependência, muitos intelectuais se notabilizaram na construção das bases teóricas e históricas para a difusão crítica, em diversos contextos políticos e sociais, nas regiões da América Latina, África e Ásia. Segundo Santos (2013), Ruy Mauro Marini inseriu o debate das grandes questões da luta revolucionária, em um campo teórico altamente abstrato, e foi capaz de iluminar os aspectos mais relevantes da realidade econômica, social e política. Por sua vez, Martins (2011) elucida que as obras de Ruy Mauro Marini constituem uma das mais importantes e originais descrições do pensamento social e do marxismo no século XX. Por tudo isso, o debate entre os intelectuais da América Latina sobre 
a teoria marxista da dependência gerou uma base teórica e histórica firme para construir uma interpretação crítica do papel da periferia no sistema capitalista mundial (Prado, 2010).

Nos seus trabalhos, Marini $(1969 ; 1973)$ aplica as categorias marxistas no estudo das realidades econômicas e políticas no processo de desenvolvimento das economias dependentes. Desse modo, define a dependência como um processo de subordinação produtiva, tecnológica e ideológica ao centro hegemônico imperialista (liderado pelos Estados Unidos da América) (MARINI, 1973). Para assegurar a reprodução ampliada da dependência, ocorre modificação ou recriação das relações de produção das nações dependentes pelo centro capitalista hegemônico.

Nesse contexto, as grandes questões econômicas e políticas, que norteiam a construção teórica da teoria marxista da dependência, centram-se na superexploração do trabalho, no intercâmbio desigual e no subimperialismo. Para Marini (2000), a superexploração do trabalho é condição necessária para o capitalismo mundial. Isso se ocorre principalmente, pelo fato de a produção capitalista ter como mecanismo fundamental para sua subexistência a criação de maisvalia (Marini, 1969). Essa é parte do valor produzido pelo trabalhador da qual se apropria o detentor dos meios de produção, o capitalista. A expansão do capitalismo global pelas regiões periféricas visa extrair a mais-valia absoluta por meio de exploração da força de trabalho. Para isso, os principais fenômenos do capitalismo global têm sido o elevado dinamismo do progresso tecnológico e a subordinação da burguesia nacional aos interesses do capital internacional. No caso concreto, o progresso tecnológico, que poupa a mão de obra e aumenta o tempo de trabalho, é frequentemente um anômalo de mais-valia absoluta (Marini, 1969).

A dependência do sistema hegemônico imperialista, nas regiões periféricas, apresenta uma realidade, a qual, por sua estrutura global e seu funcionamento, não poderá desenvolverse jamais da mesma forma como se desenvolvem nos países centrais (Marini, 1973). Há um exército de reservas nos países dependentes, aliado à baixa regulamentação das condições de trabalho, que proporciona uma maior realocação das bases produtivas para os países periféricos. Nesse ponto, Martins (2011) afirma que as contribuições teóricas de Ruy Mauro Marini (décadas de 1970s e 1980s) partem da tese objetiva de que o capitalismo é um sistema mundial hierarquizado, monopólico e desigual. Essa premissa sustenta-se no fato de o sistema criar enclaves mundiais de acumulação de capital e regiões dependentes, num processo global de transferência de valor. Sobre o resultado da relação antagônica entre as economias centrais e periféricas, defende que "[...] o desenvolvimento capitalista brasileiro se caracterizou pelas 
elevadas taxas de mais-valia, que, ao refletir um grau desproporcionado de exploração do trabalho, configuram de fato uma situação de superexploração" (Marini, 1973, p. 164-165).

Esse fenômeno é explicado visto que, à medida que se desenvolve o modo de produção capitalista e sua base tecnológica industrial, a gravitar para a mais-valia relativa, os países periféricos fundamentam seus padrões de acumulação na superexploração do trabalho (Martins, 2011). Nessa ótica, segundo Marini (1969, p. 172-73), a desvalorização constante da força de trabalho se torna um elemento decisivo na produção e acumulação capitalista. Como resultado, dessa desvalorização, a história do desenvolvimento capitalista é, neste sentido, a história da depreciação do valor real do trabalho. Por isso, para compreender o intercâmbio comercial, Marini presta atenção à análise das relações entre o centro hegemônico imperialista e as economias dependentes. A tese é que a industrialização nos países dependentes não cria a sua própria demanda, mas nasce para atender a uma demanda externa do centro hegemônico (Marini, 2000).

Nesse sentido, a divisão internacional do trabalho determina e condiciona o desenvolvimento dos países periféricos ao longo das últimas décadas. Marini (1973) observa que o crescimento da classe trabalhadora nos países centrais e a elevação da produtividade do fator trabalho resultaram no surgimento da indústria multinacional, levando em conta que a massa de matérias-primas, voltada para o processo de produção, aumentou em maior proporção. As regiões periféricas, historicamente produtoras de matérias-primas para alimentar às indústrias das metrópoles e, posteriormente, dos centros indústrias hegemônicos (liderados pelos Estados Unidos) viram-se igualmente pressionados a aumentar a produção de produtos primários.

Desse modo, a burguesia local teve um papel crucial na criação de articulações ideológicas e estruturais com as elites dos países centrais. Martins (2011) defende que setor o monopólico da burguesia, representado pelo grande capital internacional e nacional, tem a base de sua mais-valia extraordinária no monopólio setorial que exerce na economia dependente. $\mathrm{O}$ entrelaçamento dependente entre os interesses da burguesia local, limitada pelas capacidades de controle hegemônico da burguesia imperialista, dá origem às bases para criação de conclaves intermediários de produção capitalista.

Segundo Marini (1973), as regiões periféricas do sistema capitalista global, no âmbito do intercâmbio desigual, não buscam corrigir o desequilíbrio entre os preços e o valor de suas mercadorias exportadas; mas compensar a perda de renda gerada pelo comércio internacional, por meio do recurso de uma maior exploração do trabalhador. Tais desequilíbrios resultam do 
fato de a inserção dos países dependentes na economia capitalista, responder às exigências que colocam os países capitalistas, de obtenção de mais-valia relativa. Por isso, a mais-valia relativa estava ligada, indissoluvelmente, à desvalorização dos bens-salário e não à produtividade do trabalho (Marini 2000).

Destarte, cristaliza-se, nos países dependentes, um segmento monopólico da burguesia local, associado à tecnologia estrangeira, que aufere altas taxas de mais-valia e de lucro, beneficiando-se de um mercado de trabalho regido pela superexploração (MARINI, 2000). Para Marini (1967, p. 8 apud Luce, 2011a), as relações entre a burguesia nacional e o imperialismo hegemônico devem ser vistas dentro das leis da cooperação antagônica no processo de integração internacional do capitalismo. Daí o entendimento de Marini (2000, p. 137), de que as similaridades aparentes entre as economias industriais dependentes e as economias industriais desenvolvidas encobrem profundas diferenças, acentuadas pelo desenvolvimento capitalista em lugar de atenuá-las. Nesse sentido, a maior produtividade é acompanhada, efetivamente, da geração de mais-valia relativa, significando que o valor do capital variável em relação ao capital constante possibilite que se eleve a composição-valor do capital.

No curso do desenvolvimento capitalista, argumenta que os países centrais apresentam preços de produção inferiores a seus concorrentes, sem, por isso baixar significativamente os preços de mercado, expressando-se, para os países hegemônicos, em um lucro extraordinário. As transações entre as nações, que intercambiam distintos tipos de mercadorias, permitem que as demais eludam a lei do valor. Vendem seus produtos a preços superiores ao seu valor, configurando, um intercâmbio desigual, implicando que os países periféricos ou regiões dependentes cedam gratuitamente parte do valor que produzem (Marini, 2000, p. 120-121). Neste processo antagônico de relações econômicas e políticas entre a burguesia dos países dependentes e centros hegemônicos, uma nova estrutura na relação se reconfigura, isto é, o subimperialismo.

Segundo Martins (2011), Ruy Mauro Marini foi um dos primeiros intelectuais brasileiro a fazer uma análise objetiva do subimperialismo brasileiro, e das condições objetivas de expansão do capitalismo industrial no Brasil. Por sua vez, Santos (2015) argumenta que, para o caso do Brasil, o centro do poder mundial (comandado pelos Estados Unidos), se expandiu, depois do Golpe de Estado de 1964. Nesse sentido, Marini (1969) sustenta que "[...] a reativação da acumulação nos marcos tratados pelo modelo subimperialista em 1964 dependia inteiramente da inversão da tendência de altos salários o que significava a reafirmação da 
superexploração do trabalho. Para tal, a acumulação de capital seria determinada pela relação entre os dois tempos constitutivos da jornada de trabalho" (Marini, 1969, p. 171).

Para Marini (1974), a tese central do eixo do subimperialismo é constituída pelo problema ou limitação do mercado nos países imperialistas. Na visão de Luce (2011b), Marini estabelece o conceito de subimperialismo para explicar a nova divisão internacional do trabalho, e da emergência de sub-centros econômicos e políticos da acumulação mundial; regiões intermediárias de acumulação capitalistas entre os centros hegemônicos e os países dependentes. Martins (2011) afirma que o subimperialismo, teorizado por Ruy Mauro Marini, na década de 1970, se caracteriza, do ponto de vista econômico, pelo alto dinamismo das exportações de mercadorias, pela exportação de capital e pelo controle regional de matériasprimas e suprimentos energéticos.

Marini (1992) fundamenta que, em razão deste novo dinamismo externo, centrado nas exportações de produtos primários, o subimperialismo corresponderia à expressão perversa da diferenciação sofrida pela economia mundial. Assim sendo, defende, ainda, o pressuposto de que o subimperialismo cria uma composição orgânica média na escala mundial dos aparatos produtivos nacionais e uma política expansionista relativamente autônoma. Entretanto, essa autonomia das regiões intermediárias de acumulação não é acompanhada de uma maior integração ao sistema produtivo imperialista, tornando-a dependente da hegemonia exercida pelo imperialismo em escala internacional.

Na ótica de Marini (1969, p. 246), os governos ditatoriais na América Latina (Brasil 1964, Chile - 1973) foram instrumento e resultado de um desenvolvimento de tipo capitalista de Estado e subimperialista. Nessa perspectiva, a criação de condições de mobilização e organização das classes trabalhadoras e da pequena-burguesia para revolução apresenta-se como único caminho para a implantação de uma plataforma socialista na região. Ademais, considera-se que o caráter social e econômico das lutas políticas na América Latina torna imprescindível, para o controle dos meios de produção e do Estado pelas classes trabalhadoras, a via da revolução continental. Portanto, cabe apontar, ainda, a necessidade de construção de um partido que reflita a hegemonia do proletariado, segundo o qual os seus interesses primem no programa revolucionário das classes trabalhadoras (MARINI, 1969, p. 259).

Assim sendo, entende-se que, para um desenvolvimento autônomo dos países periféricos, é vital a construção de uma hegemonia do proletariado, que, com o objetivo de construir uma plataforma socialista inclusiva, leve as agendas das classes trabalhadoras para o campo político. Ruy Marini considera com sua obra que o desenvolvimento decorre de um 
processo de lutas e conquistas da classe trabalhadora e da pequena-burguesia. Defende a existência de um dever histórico dessas classes em contribuir no processo de articulação e acumulação produtiva do capital e no desenvolvimento nacional. O caminho é a revolução, pois sem essa, as condições materiais para o desenvolvimento autônomo da periferia serão ditadas pelo Estado capitalista ou subimperialista, deixando pouco espaço de participação e mobilização necessárias do proletariado e da pequena-burguesia.

\section{Considerações finais}

O desenvolvimento capitalista, para Furtado, gera, no seu curso, o subdesenvolvimento, o qual, nessa perspectiva, não constitui uma etapa, um estágio ou uma fase do desenvolvimento, ao contrário, estão intrinsecamente vinculados. O sistema, ao se desenvolver, gera estruturas econômicas heterogêneas, promovendo desigualdade social, em distintos espaços nacionais. Todavia, alguns países constroem trajetórias de desenvolvimento autônomas, enquanto outros, o fazem de forma subordinada, submissa e dependente. No curso do processo histórico, decisões são tomadas por atores sociais sobre estruturas econômicas estabelecidas, afetando a trajetória do desenvolvimento. E, ressalta-se, muitas dessas não estão vinculadas aos interesses maiores da sociedade, mas, sim, à manutenção de determinado grupo de atores sociais.

No Brasil, o processo de desenvolvimento foi marcado, historicamente, por uma dinâmica geradora de dependência, que, segundo Furtado, é cultural, estabelecendo-se, aqui, um padrão de desenvolvimento fundado em reproduzir o sistema produtivo e de consumo dos países centrais, distinto das condições econômicas e sociais de um país periférico. Com isso, firmou-se uma estrutura econômica interna dotada de capacidade de preservação, sustentada por determinado estímulo externo. A produção organizou-se de forma seletiva, com técnicas intensivas em capital e poupadora de mão de obra, cujos ganhos de produtividade não foram transferidos para o conjunto da sociedade, mas, sim, para certo grupo social. Constituiu-se uma estrutura econômica deformada, com presença de segmentos atrasado e moderno; sendo esse último produtor de bens de luxo e diversificados, com acesso aos produtos importados, gerador de bem-estar e vinculado a consumidores de renda elevada.

Ainda, segundo Furtado, tal processo dependencista na sociedade brasileira fora sustentado pelo mimetismo de valores culturais e ideológicos do centro. Essa forma de desenvolver o capitalismo brasileiro permitiu que grupos sociais internos, detentores de poder 
e capital, se beneficiassem, se reproduzissem e subjugassem estratos sociais inferiores. Para tanto, o sistema criou valores mantenedores, como facilidade de ingresso de capitais estrangeiros, sistema de propaganda e comunicação em favor do consumo conspícuo, difusão de valores emuladores na sociedade, financiamento dos bens produzidos etc. Esse sistema, por um lado, levou o país a um aprisionamento instrumental cognitivo, constrangedor para a busca de outras alternativas de desenvolvimento. Por outro lado, desenvolveu estrutura econômica produtora de heterogeneidade social, excluindo parcela significativa da população do acesso aos bens e serviços, necessários para se viver de forma digna na sociedade.

Entretanto, Furtado tinha esperança que o país encontraria saída para superar as amarras do subdesenvolvimento, e caminhar para a construção de uma sociedade em direção a homogeneidade social. O caminho de superação apontado passava pela vontade política da sociedade, desejosa de reconstruí-la sob novas bases econômicas e sociais. Nesse curso, caberia ao Estado grande responsabilidade, considerando, principalmente, que ele deveria ser refundado, reconstruído. A partir do exercício de funções de criação, organização e controle do aparato estatal, abririam-se espaços institucionais para aflorar a criatividade humana em diferentes foros. O propósito principal seria: potencializar o desenvolvimento da nossa cultura no caminho da construção de uma sociedade mais justa, igualitária e fraternal; uma tarefa considerada difícil de ser levada a cabo, mas não impossível, dada a estrutura de dominação existente.

$\mathrm{Na}$ perspectiva analítica de Cardoso, em seus trabalhos individuais e em parceria, o desenvolvimento constitui um processo social, mesmo que seja visto pelos aspectos econômicos. No interior ocorrem lutam políticas entre as forças sociais que se manifestam, através de objetivos e interesses voltados em dar direção no rumo do desenvolvimento da sociedade. Assim, o desenvolvimento deve ser considerado a partir da análise das relações entre os grupos sociais, estando em pauta a estrutura de dominação - controle e decisão - e a relação com os estratos da estrutura social existente. O curso do desenvolvimento ocorre sob movimento de lutas política e econômica, na esteira de processo histórico, particular de cada país. Nesse processo, confere-se o conceito de dependência, que se manifesta a partir de relações estruturais internas - interesses de grupos e classes sociais - com parceiros externos, forâneos.

No entendimento de Cardoso, estabelece-se no Brasil a dependência política, manifestada pela opção de desenvolvimento a partir de vínculos dos interesses internos aos do capital internacional. Os esforços de construir industrialização autônoma não se viabilizaram 
diante das crises econômica e política, que se instauraram no limiar dos anos 60 , e da falta de hegemonias política e econômica. Em particular destaque-se o empresariado nacional, caracterizado como amorfo, apático e sem iniciativa para formular um projeto que levasse o país ao desenvolvimento autônomo. Instaurou-se, a partir de então, um capitalismo dependente associado, constituído por empresas do setor produtivo estatal, empresas multinacionais de grande porte e empresas nacionais locais vinculadas a ambas.

Nesse curso, consolidou-se o projeto de desenvolvimento com interferência de grupos sociais estranhos à economia doméstica. Essa decisão, que se iniciou na segunda metade dos anos 50, manifestou-se pela adesão ao processo de internacionalização do mercado, como caminho para o desenvolvimento. Com isso, entrelaçaram-se os interesses de poder e de alianças de grupos e frações de classes internas e forâneas. Contudo, tal quadro, antes de apresentar característica disfuncional, estabeleceu uma dependência instaurada, a qual, para o Cardoso, constitui um modus operandi do capitalismo na periferia. Caberia ao Estado, nesse caso, a função de regular, intervir e promover o desenvolvimento capitalista sob esta forma de dominação.

Em outra perspectiva teórica analítica, Ruy Mauro Marini explica a dependência a partir da teoria marxista, como meio para entender as dinâmicas paradoxais do desenvolvimento capitalista nas regiões periféricas. Assim, partiu do conceito de superexploração do trabalho, visto como condição necessária e histórica do desenvolvimento do capitalismo, para, então, discutir as configurações de que os países imperialistas hegemônicos extraem a mais-valia absoluta pela exploração do trabalho. Na visão de Marini, dois fatores permitem uma inserção subordinada do capital hegemônico na periferia do sistema: 1) os avanços tecnológicos na grande indústria, que proporcionam uma redução do tempo do trabalho necessário, sem aumento no salário ao trabalhador; e 2) as articulações da burguesia nacional como as elites hegemônicas pelo monopólio setorial, extraindo uma mais-valia relativa dentro do processo de acumulação. Nesse contexto, o desenvolvimento da estrutura industrial brasileira encontra-se condicionada aos ditames do padrão tecnológico ditado pelo país hegemônico (Estados Unidos) e a participação da indústria nacional no sistema produtivo global se dá por meio de mercadorias e produtos primários, além da desvantagem de preços baixos no mercado internacional para os países periféricos.

Partindo desse debate, Ruy Mauro Marini aponta que os termos de troca são desiguais entre a periferia e o centro hegemônico do sistema capitalista. $\mathrm{O}$ autor afirma, ainda, que o sistema capitalista hegemônico cria "enclaves de acumulação", ou seja, regiões semiperiféricas, 
onde os países nessas condições exercem um Estado do tipo capitalista e subimperialismo. $\mathrm{Na}$ região da América Latina, o Brasil é o único país com condições institucionais, produtivas e políticas para exercer o subimperialismo. Por fim, Marini traça as linhas gerais para a superação do subdesenvolvimento nas regiões periféricas, orientando para: a) uma maior mobilização e organização hegemônica do proletariado e da pequena-burguesia; b) a criação de uma base política com caráter social e econômico para a edificação de um Estado fundado numa plataforma socialista; e c) uma mobilização da região da América Latina rumo à revolução continental.

\section{Referências}

ALBUQUERQUE, E. M. A. Celso Furtado, a polaridade modernização-marginalização e uma agenda para a construção dos sistemas de inovação e de bem estar social. In.: SABOIA, J.; CARVALHO, F. J. (org.) Celso Furtado e o século XXI. Barueri, SP: Manole; Rio de Janeiro: Instituto de Economia da Universidade Federal do Rio de Janeiro, 2007, p. 181- 204.

ALMEIDA, J. E. Subdesenvolvimento e dependência: uma análise comparada de Celso Furtado e Fernando Henrique Cardoso. 205 fl. Tese (Doutorado em Economia), Programa de Pós-Graduação em Economia, Universidade Federal do Rio Grande do Sul, 2009.

AREND, M.; FAGOTTI, V. Z.; MOREIRA, A. G. Cultura e histerese institucional: a dependência furtdiana como uma instituição histórica. Revista Nova Economia, v. 29, n. especial, p. 1305 - 1330, 2019.

BRANDÃO, C. Celso Furtado: subdesenvolvimento, dependência, cultura e criatividade. Revista de Economia Política de las Tecnologias de la Información y de la Comunicaión. Vol. XIV, n. 1, ene-abr, 2012, 11 p.

CAETANO, J. E. B.; MISSIO, F. J. Notas sobre o papel da cultura no desenvolvimento de Celso Furtado. Texto de Economia, v. 20, n. 1, p. 19-35, 2017.

CARDOSO, F. H. Empresário industrial e desenvolvimento econômico no Brasil. São Paulo: Difusão Européia do Livro, 1964.

CARDOSO, F. H. Mudanças sociais na América Latina. São Paulo: Difusão Européia do Livro, 1969.

CARDOSO, F. H. As idéias e seu lugar: ensaios sobre as teorias do desenvolvimento. Petrópolis: Vozes, 1993.

CARDOSO, F. H.; FALETTO, E. Dependência e desenvolvimento na América Latina: Ensaio de interpretação sociológica. 3a . ed. Rio de Janeiro: Zahar, 1975. 
CARDOSO, F. H.; IANNI, O. "As exigências educacionais do processo de desenvolvimento". Revista Brasiliense, nº 26, São Paulo, nov.- dez. 1959.

FIORI, J. L. De volta à questão da riqueza de algumas nações. FIORI, J. L. (org.) Estado e moeda no desenvolvimento das nações. Petrópolis: Vozes, 1999, p. 11-46.

FURTADO, C. Um projeto para o Brasil. Rio de Janeiro: Editora Saga, 1968.

FURTADO, C. Dependência externa y teoria econômica. El Trimestre Económico. Vol. XXXVIII, no. 150. México, abr-jun, p. 23 - 37, 1971.

FURTADO, C. Análise do modelo brasileiro. Rio de Janeiro: Civilização Brasileira, 1972.

FURTADO, C. O mito do desenvolvimento econômico. Rio de Janeiro: Paz e Terra, 1974.

FURTADO, C. Pequena introdução ao desenvolvimento: enfoque interdisciplinar. São Paulo: Editora Nacional, 1980.

FURTADO, C. Teoria e política do desenvolvimento econômico. São Paulo: Abril Cultural, 1983.

FURTADO, C. Cultura e desenvolvimetno em época de crise. $2^{\mathrm{a}}$. ed. Rio de Janeiro: Paz e Terra, 1984.

FURTADO, C. O subdesenvolvimento revisitado. Economia e Sociedade, 1(1), 5-19. agosto de 1992.

FURTADO, C. O capitalismo global. Rio de Janeiroi: Paz e Terra, 1998.

FURTADO, C. O longo amanhecer: reflexões sobre a formação do Brasil. 2a ${ }^{a}$ ed. Rio de Janeiro: Paz e Terra, 1999.

FURTADO, C. Estão liquidando a soberania nacional. In: BENJAMIN, C.; ELIAS, L. A. (orgs.) Brasil: crise e destino - entrevistas com pensadores contemporâneos. São Paulo: Expressão Popular. 2000. p. 15 - 20.

IPIRANGA, H. A.; AREND, M. Fundamentos microdinâmicos do subdesenvolvimento: aportes evolucionários à teoria da dependência de Celso Furtado. Textos de Economia, v. 23, n. 2, p. 1-23, dez; mar, 2020.

LINS, L. C. O. Desenvolvimento social: o projeto de Celso Furtado para a nação brasileira. 149 fl. (Dissertação de Economia), Programa de Pós-Graduação em Economia e Desenvolvimento. Universidade Federal de Santa Maria, 2013.

LUCE, M. S. A economia política do sub-imperialismo em Ruy Mauro Marini: uma história conceitual. Anais... XXVI Simpósio Nacional de História - ANPUH, São Paulo, julho 2011a. 
LUCE, M. S. A teoria do subimperialismo em Ruy Mauro Marini: contradições do capitalismo dependente e a questão do padrão de reprodução do capital. A História de uma categoria. 225 fl. Tese (Doutorado em História). Programa de Pós-Graduação em História, Universidade Federal do Rio Grande do Sul. 2011b.

MARINI, R. M. Subdesarrollo y revolución, Ed. Siglo XXI, México D.F., 1969.

MARINI, R. M. Dialéctica de la dependencia: la economía exportadora, em Tres ensayos sobre América Latina, Ed. Anagrama, Barcelona, 1973 [1972].

MARINI, R. M. América Latina - dependência e integração, São Paulo, Página Aberta, 1992.

MARINI, R. M. Dialética da dependência. Petrópolis: Vozes, 2000.

MARTINS. C. E. Mauro Marini e sua atualidade: reflexões para o século XXI. Crítica Marxista, n.32, p.127-146, 2011.

MARTINS, L. Industrialização, burguesia nacional e desenvolvimento - introdução a crise brasileira. Rio de Janeiro: Saga, 1968.

MELO, J. M. Capitalismo tardio. Rio de Janeiro: Brasiliense, 1983.

PACHECO, A. P. C.; BENINI, E. G. A economia criativa em época de crise: o desenvolvimento endógeno brasileiro na obra de Celso Furtado. Revista de Economia Política. Vol. 38, no. 2 (151), pp. 324-337, abril-junho, 2018.

PRADO, F. C. História de um não-debate: a trajetória da teoria marxista da dependência no Brasil. Comunicação \& Política, v. 29, n. 2, p. 68-94, 2010.

PRADO, F. C. A ideologia do desenvolvimento e a controvérsia da dependência no Brasil contemporâneo. Tese (Doutorado em Política Internacional). Programa de Pós-Graduação em Economia Política Internacional, Universidade Federal do Rio de Janeiro, 2015.

SAMPAIO JR., P. A. O impasse da formação nacional. In: FIORI, J. L. (org.). In: Estados e moedas no desenvolvimento das nações. $3^{\mathrm{a}}$. ed. Rio de Janeiro: Vozes, 1999, p. 415-448.

SANTOS, T. Teoria da dependência: balanço e perspectivas. Editora Insular. Volume 1, Florianópolis, 2015.

SIGAÚQUE, E. S. Capitalismo africano dependente: estudo histórico-estrutural da economia moçambicana entre o período de 1985-2015. 2017. 231 f. Dissertação (Mestrado em Economia)

- Programa de Pós-Graduação em Economia, Universidade Federal de Santa Catarina, Florianópolis, 2017.

SUZIGAN, W. Indústria brasileira - origem e desenvolvimento. Rio de Janeiro: Brasiliense, 1986.

TAVARES, M. C. Da substituição de importações ao capitalism financeiro - ensaios sobre economia brasileira. 6a. ed. Rio de Janeiro: Zahar Ed. 1977. 
VILAÇA, A.; CONCEIÇÃO, O. A. Dinâmica do desenvolvimento periférico latino-americano: uma conformação institucional. Anais...XIX Encontro de Economia da Região Sul da Associação Nacional dos Programas de Pós-Graduação em Economia. Florianópolis, Universidade Federal de Santa Catarina, 2016. 16 p. 